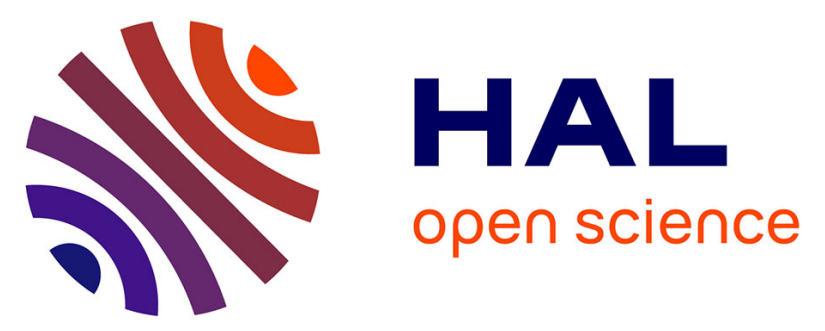

\title{
Room Temperature Blocked Magnetic Nanoparticles Based on Ferrite Promoted by a Three-Step Thermal Decomposition Process
}

Kevin Sartori, Fadi Choueikani, Alexandre Gloter, Sylvie Bégin-Colin, Dario Taverna, Benoît Pichon

\section{To cite this version:}

Kevin Sartori, Fadi Choueikani, Alexandre Gloter, Sylvie Bégin-Colin, Dario Taverna, et al.. Room Temperature Blocked Magnetic Nanoparticles Based on Ferrite Promoted by a Three-Step Thermal Decomposition Process. Journal of the American Chemical Society, 2019, 141 (25), pp.9783-9787. 10.1021/jacs.9b03965 . hal-02383685

\section{HAL Id: hal-02383685 https://hal.science/hal-02383685}

Submitted on 17 Nov 2020

HAL is a multi-disciplinary open access archive for the deposit and dissemination of scientific research documents, whether they are published or not. The documents may come from teaching and research institutions in France or abroad, or from public or private research centers.
L'archive ouverte pluridisciplinaire HAL, est destinée au dépôt et à la diffusion de documents scientifiques de niveau recherche, publiés ou non, émanant des établissements d'enseignement et de recherche français ou étrangers, des laboratoires publics ou privés. 


\title{
Room Temperature Blocked Magnetic Nanoparticles Based on Ferrite Promoted by a Three-Step Thermal Decomposition Process
}

\author{
Kevin Sartori, ${ }^{\dagger, \ddagger \odot}$ Fadi Choueikani, ${ }^{\ddagger}$ Alexandre Gloter, ${ }^{\S}$ Sylvie Begin-Colin, ${ }^{\dagger} \odot$ Dario Taverna," \\ and Benoit P. Pichon $*,+\perp \odot$ \\ ${ }^{\dagger}$ Université de Strasbourg, CNRS, Institut de Physique et Chimie des Matériaux de Strasbourg, UMR 7504, F-67000 Strasbourg, \\ France \\ ${ }^{\ddagger}$ Synchrotron SOLEIL, L’Orme des Merisiers, Saint Aubin - BP48, 91192 Gif-sur-Yvette, France \\ ${ }^{\S}$ Laboratoire de Physique des Solides, CNRS, Université Paris-Sud UMR 8502, 91400 Orsay, France \\ "Institut de Minéralogie, de Physique des Matériaux et de Cosmochimie (IMPMC), Sorbonne Université, 75005 Paris, France \\ ${ }^{\perp}$ Institut Universitaire de France, 1 rue Descartes, 75231 Paris Cedex 05, France
}

ABSTRACT: Exchange coupled nanoparticles that combine hard and soft magnetic phases are very promising to enhance the effective magnetic anisotropy while preserving sizes below $20 \mathrm{~nm}$. However, the core-shell structure is usually insufficient to produce rare earth-free ferro(i)magnetic blocked nanoparticles at room temperature. We report on onion-type magnetic nanoparticles prepared by a three-step seed mediated growth based on the thermal decomposition method. The core@shell@shell structure consists of a core and an external shell of $\mathrm{Fe}_{3-\delta} \mathrm{O}_{4}$ separated by an intermediate Co-doped ferrite shell. The double exchange coupling at both core@shell and shell@ shell interfaces results in such an increased of the magnetic anisotropy energy, that onion-type nanoparticles of $16 \mathrm{~nm}$ mainly based on iron oxide are blocked at room temperature. We envision that these results are very appealing for potential applications based on permanent magnets.

$\mathrm{H}$ ard-soft coupled magnetic nanoparticles have gained a tremendous amount of interest during the past decade for short-term development of advanced applications related to spintronics (magnetoresistive sensors, magnetic recording, etc.). ${ }^{1}$ Indeed, they are a potential alternative to produce permanent magnets ${ }^{2}$ in order to circumvent supply storage caused by the critical need for rare earth elements in communications and mobility applications. With this purpose, the main goal is to overcome superparamagnetism, which results from size reduction to the nanoscale. ${ }^{3}$ A very attractive approach is the design of core-shell nanoparticles that combine hard and soft magnetic phases in direct contact. ${ }^{4}$ Thanks to the large core-shell interface, exchange coupling between interfacial spins of both phases can be finely modulated by a collection of parameters such as core size and shell thickness, ${ }^{5,6}$ as well as crystal lattices mismatch, defects $^{7}$ and cationic diffusion. ${ }^{8,9}$ Therefore, exchange coupling results in the enhancement of thermal stability (higher blocking temperature, $T_{\mathrm{B}}$ ) and magnetic stability (higher coercive field, $H_{\mathrm{C}}$ ). In this field, iron oxide is certainly the first choice to avoid rare earth components because of its abundance, nontoxicity and low cost. ${ }^{10}$ Indeed, ferr(i)magnetic $(\mathrm{F}(\mathrm{i}) \mathrm{M})$ ferrites are usually combined with an antiferromagnetic (AFM) phase such as $\mathrm{MnO} @ \mathrm{Mn}_{3} \mathrm{O}_{4},{ }^{11} \mathrm{Fe}_{3-\delta} \mathrm{O}_{4} @$ $\mathrm{CoO},{ }^{5,12} \mathrm{CoO} @ \mathrm{CoFe}_{2} \mathrm{O}_{4}{ }^{13}$ and $\mathrm{ZnO} @ \mathrm{Co}_{x} \mathrm{Zn}_{1-x} \mathrm{Fe}_{2} \mathrm{O}_{4} \cdot{ }^{14}$

Nevertheless, the AFM order vanishes below the Neel temperature (for instance, $T_{\mathrm{N}}=290 \mathrm{~K}$ for CoO) which results in the disappearance of the exchange bias coupling. It is an important drawback for the design of room temperature permanent magnets. Recently, the magnetic anisotropy energy of Co@CoO nanoparticles incorporated in a $\mathrm{NiO}$ matrix $\left(T_{\mathrm{N}}\right.$ $=520 \mathrm{~K}$ ) was enhanced above room temperature thanks to proximity effects. ${ }^{15}$ However, in this approach, nanoparticles cannot be manipulated as separate building blocks for the production of advanced technological devices. An alternative to AFM components is the design of nanoparticles that combine multiple $\mathrm{F}(\mathrm{i}) \mathrm{M}$ phases. Ferrites $\left(\mathrm{MFe}_{2} \mathrm{O}_{4}\right.$, with $\mathrm{M}$ : $\mathrm{Co}, \mathrm{Mn}, \mathrm{Ni}$ ), which exist in several chemical compositions, allow the fine modulation of hardness and softness of the magnetic phases. ${ }^{6,16}$ For instance, the diffusion of $\mathrm{Co}^{2+}$ in the surface layer of a $\mathrm{Fe}_{3-\delta} \mathrm{O}_{4}$ core resulted in the formation of a Co-doped ferrite shell which markedly increased of magnetic anisotropy energy. ${ }^{5,17}$ Furthermore, recent advances in synthesis techniques allowed the production of multiple shell nanoparticles. ${ }^{18-20}$ Although $T_{\mathrm{B}}$ remains below room temperature, onion-type nanoparticles offer the potential to produce permanent magnets.

Here, we report on an original strategy to synthesize oniontype nanoparticles that are ferrimagnetic at room temperature and mainly consist of iron oxide with a mean size that does not exceed 16 nm. These nanoparticles consist of a core@shell@ shell structure, with a intermediate shell which mostly consists in Co-ferrite The significant enhancement of the magnetic properties at room temperature is ascribed to double interfacial exchange coupling at core/shell and shell/shell interfaces.

Nanoparticles were synthesized by a three-step thermal decomposition method. First, $\mathrm{Fe}_{3-\delta} \mathrm{O}_{4}$ nanoparticles (C) were prepared by performing the thermal decomposition of iron 

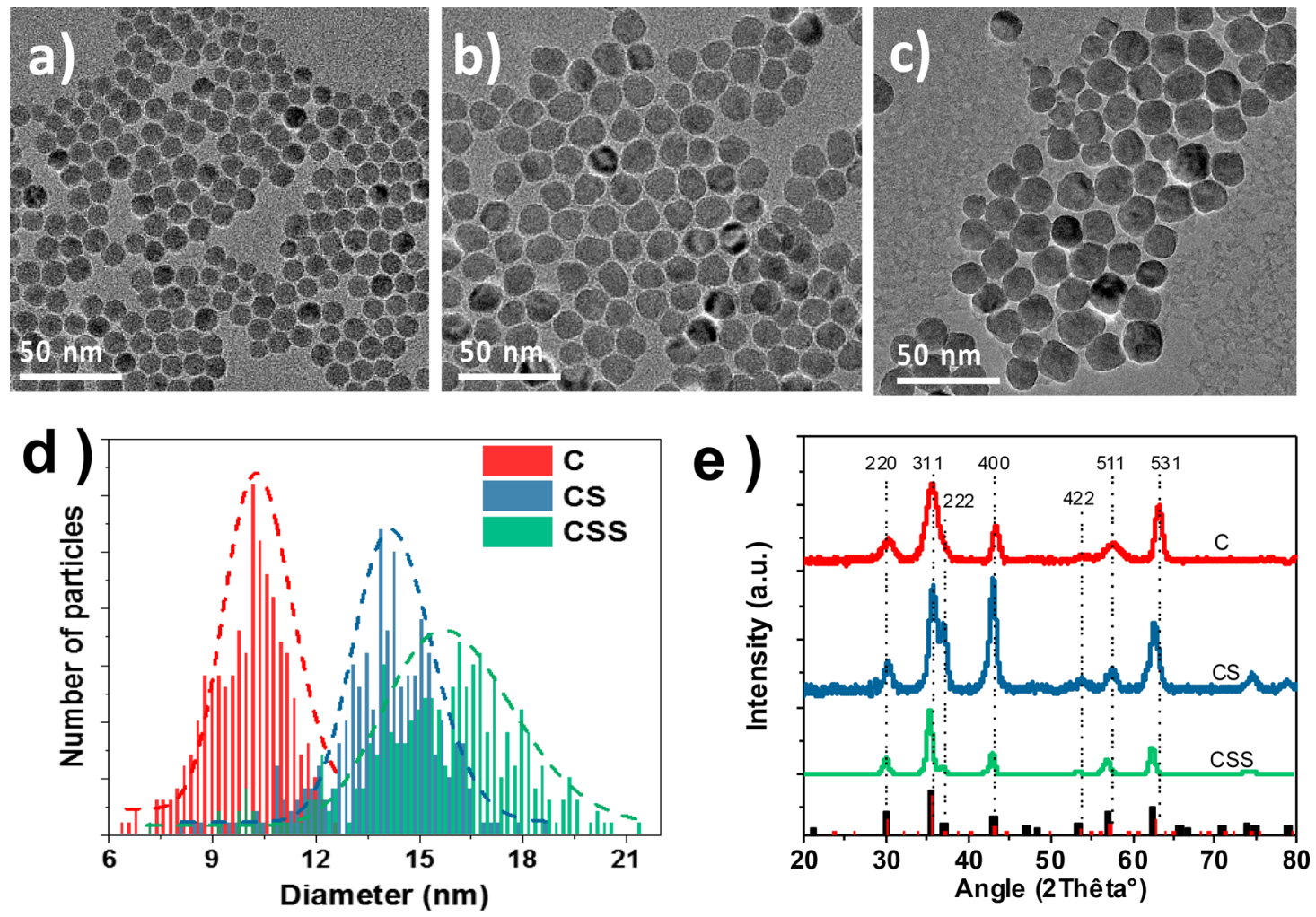

Figure 1. TEM micrographs of (a) C, (b) CS and (c) CSS nanoparticles. (d) Size distributions measured from TEM micrographs. (e) XRD patterns. Black and red bars correspond to the spinel structures $\left(\mathrm{Fe}_{3} \mathrm{O}_{4}\right.$ JCPDS card no. 19-062 and $\mathrm{CoFe}_{2} \mathrm{O}_{4}$ JCPDS card no. 22-1086) and the $\mathrm{CoO}$ wüstite structure (JCPDS card no. 70-2856), respectively.

stearate in dioctyl ether at $290^{\circ} \mathrm{C}$ in the presence of oleic acid. Second, cobalt stearate was decomposed in octadecene at 310 ${ }^{\circ} \mathrm{C}$ in order to grow a $\mathrm{CoO}$ shell on the $\mathrm{Fe}_{3-\delta} \mathrm{O}_{4}$ surface (CS). Third, iron stearate was again decomposed in order to grow a second shell of $\mathrm{Fe}_{3-\delta} \mathrm{O}_{4}$ (CSS). Both shells were formed successively through a seed mediated growth by controlling carefully the synthesis conditions. Nanoparticles were isolated after each step in order to avoid any side reactions resulting from the presence of side products and remaining metal stearate.

Transmission electron microscopy (TEM) micrographs show the increase of the mean nanoparticle size after each decomposition step from $10.1 \pm 1.1 \mathrm{~nm}(C), 14.0 \pm 1.5 \mathrm{~nm}$ (CS) to $15.6 \pm 2.3 \mathrm{~nm}$ (CSS), respectively (Figure 1a-d). Xray diffraction (XRD) patterns display typical peaks of the spinel structure (Figure 1e). Additional peaks corresponding to the wüstite $\mathrm{CoO}$ phase were observed in the CS pattern and almost vanished in the CSS pattern. Furthermore, spinel peaks became narrower after each growth step which corresponds to the increase of larger crystal sizes $(6.1 \pm 0.1 \AA$ (C), $7.9 \pm 0.1 \AA$ (CS) and $11.0 \pm 0.1 \AA$ (CSS)) and agree with larger nanoparticles. Energy-dispersive X-ray spectroscopy (EDX) analysis performed on several nanoparticles showed the presence of Co with a $\mathrm{Fe}$ :Co atomic ratio of 45:55 in CS which increased to $73: 27$ in CSS, consistent with the growth of a Fe-rich shell.

Furthermore, the scanning transmission electron microscopy electron energy loss spectroscopy (STEM-EELS) elemental mapping recorded at $\mathrm{Fe}-\mathrm{L}$ and $\mathrm{Co}-\mathrm{L}$ edges showed that $\mathrm{Co}$ is not homogeneously distributed across CSS nanoparticles (Figure $2 \mathrm{~b}, \mathrm{~d}$ ). This result was confirmed by EELS spectra recorded in different areas (Figure 2d,e) which show different
Co content. STEM-EELS analysis on CS also showed that $\mathrm{CoO}$ seems to grow preferentially on specific facets of the $\mathrm{Fe}_{3-\delta} \mathrm{O}_{4}$ core and resulted in an irregular shell shape (Figure S1). ${ }^{5}$ This is consistent with the more faceted morphology of CS nanoparticles in comparison with $\mathrm{C}$ nanoparticles (Figure $1 \mathrm{a}, \mathrm{b})$. Nevertheless, the overall amount of CoO-rich phase is much lower in CSS than in CS as shown by XRD. Indeed, the CSS edge (area B) displays a Fe:Co ratio of $2.0 \pm 0.3$, consistent with a Co-doped ferrite.

STEM high-angle annular dark-field (HAADF) micrographs revealed lattice fringes across CSS (Figure 2a and S2) which agree with the high crystallinity of the spinel structure. A $d$ spacing of $2.423 \AA$, consistent with the [222] direction and a cell parameter of $8.893 \AA$, were calculated from fast Fourier transform (FFT) (Figure S3). The doubling of lattice fringes was also observed in Co-rich areas with a $d$-spacing of $2.461 \AA$, consistent with the [111] direction of wüstite $\mathrm{CoO}$ phase. The perfect interpenetration of fringes corresponding to spinel and wüstite structures shows the good epitaxial relationship. Indeed, geometric phase analysis revealed a lattice expansion of $1-2 \%$ which agrees with the small lattice mismatch of $1.6 \%$ when crossing spinel wüstite structures.

To confirm these results, we investigated the chemical composition of CSS and site occupancy of Fe and Co cations by performing X-ray magnetic circular dichroism (XMCD) measurements (Figure 3). ${ }^{21}$ At the $\mathrm{Fe}-\mathrm{L}_{2,3}$ edge, peaks correspond to $\mathrm{Fe}^{2+}$ and $\mathrm{Fe}^{3+}$ cations in $\mathrm{Oh}$ sites (S1), $\mathrm{Fe}^{3+}$ in $\mathrm{Td}$ sites (S2) and $\mathrm{Fe}^{3+}$ in Oh sites (S3) of the ferrite spinel structure. The $\mathrm{S} 1+\mathrm{S} 2 / \mathrm{S} 2+\mathrm{S} 3$ ratio $(0.95)$ is intermediate to $\mathrm{Fe}_{3} \mathrm{O}_{4}$ (1.27) and $\gamma-\mathrm{Fe}_{2} \mathrm{O}_{3}(0.61) .{ }^{17}$ It agrees with the low occupancy of $\mathrm{Fe}^{2+}$ in Oh sites. At the Co- $\mathrm{L}_{2,3}$ edge, a peak (S4) corresponds to $\mathrm{Co}^{2+}$ in $\mathrm{Oh}$ sites of a Co-ferrite. ${ }^{22}$ Such an 

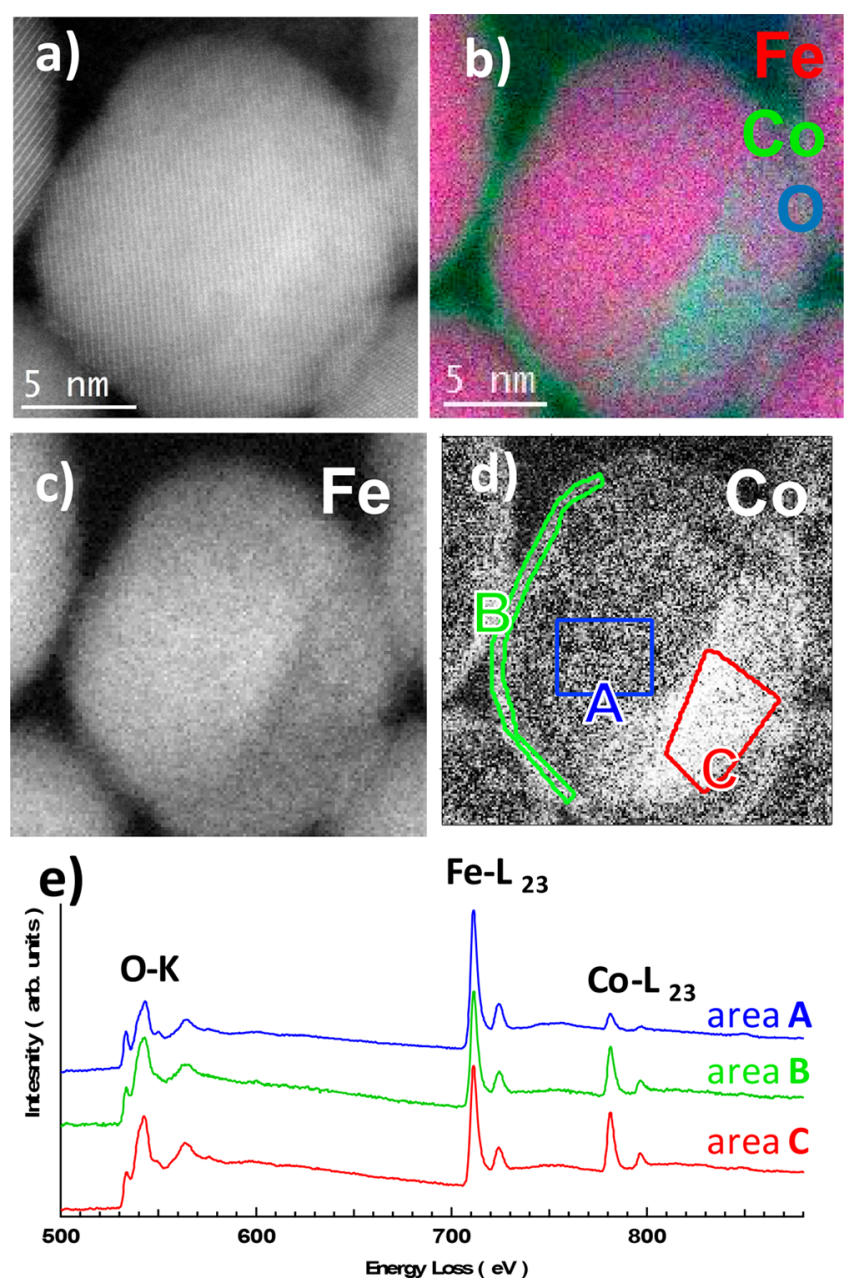

Figure 2. CSS nanoparticles. (a) Dark field STEM-HAADF micrograph. STEM-EELS micrographs : (b) composite image showing the distribution of $\mathrm{Fe}$ (red), Co (green) and $\mathrm{O}$ (blue) species, (c) Fe map, (d) Co map and (e) EELS spectra corresponding to different areas as selected in panel $\mathrm{d}$.

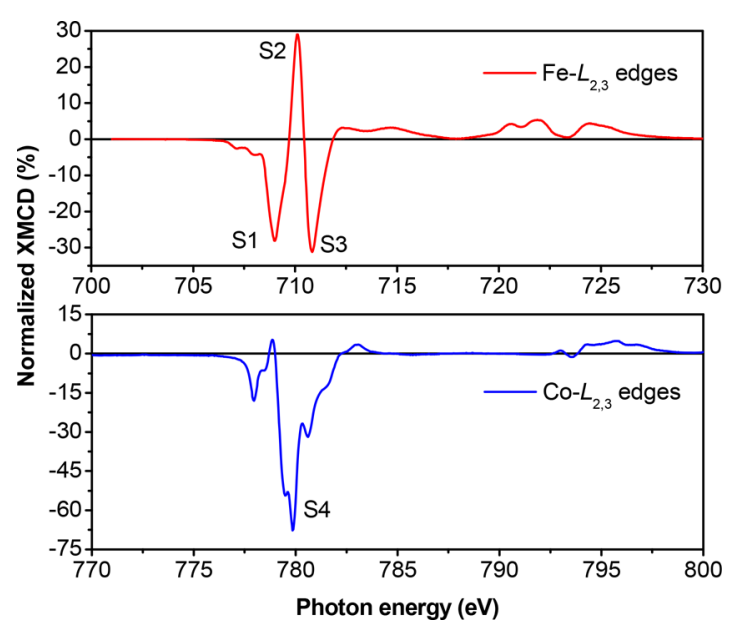

Figure 3. XMCD spectra of CSS nanoaprticles.

intense peak cannot be ascribed to the CoO AFM phase. Indeed, XMCD being sensitive to the polarization of magnetic moments, spins of $\mathrm{Co}^{2+}$ which are coupled antiparallel in $\mathrm{CoO}$ cannot contribute to the signal.
The magnetic properties of the nanoparticles were studied by SQUID magnetometry. $\mathrm{M}(\mathrm{H})$ curves of CSS nanoparticles display a coercive field $\left(H_{\mathrm{C}}\right)$ of $500 \mathrm{Oe}$ at $300 \mathrm{~K}$ in contrast to $\mathrm{C}$ and $\mathrm{CS}$ nanoparticles $\left(H_{\mathrm{C}}=0\right)$ (Figure $\left.4 \mathrm{~b}\right)$. This result was
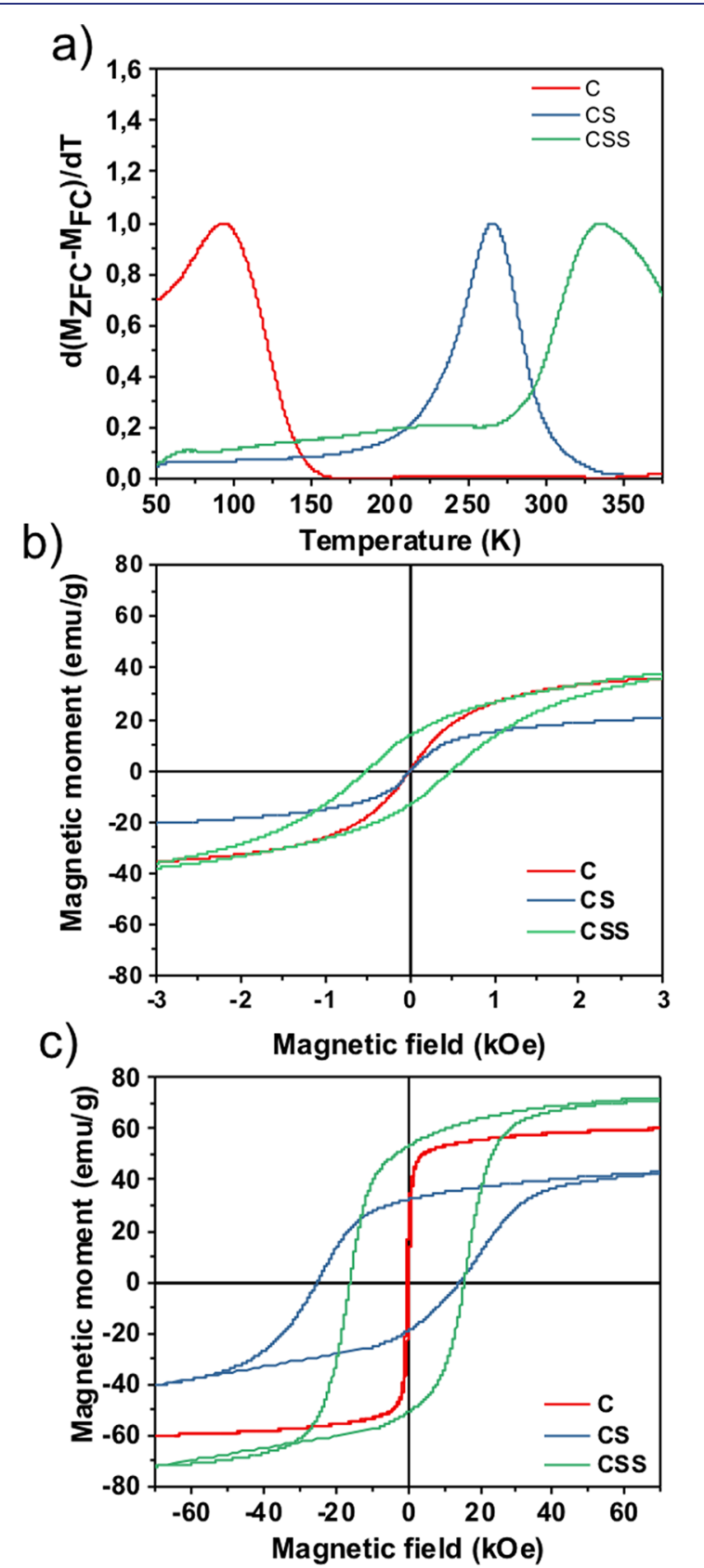

Figure 4. Magnetic properties of C, CS and CSSC nanoparticles. (a) Distribution of blocking temperatures $M(H)$ curves recorded at (b) $300 \mathrm{~K}(\mathrm{ZFC})$ and (c) $10 \mathrm{~K}$ (FC under $7 \mathrm{~T}$ ).

confirmed by $M(T)$ curves (Figure S4) and the corresponding distribution of blocking temperatures $\left(T_{\mathrm{B}}\right)$ (Figure $\left.4 \mathrm{a}\right),{ }^{14,23}$ i.e. the temperature below which the magnetic moments of nanoparticles are blocked. $T_{\mathrm{B}}$ gradually increases with the formation of shells and clearly raises up above room temperature $(340 \mathrm{~K})$ for CSS. This value is much higher than the one of $\mathrm{Fe}_{3-\delta} \mathrm{O}_{4}$ nanoparticles of $15 \mathrm{~nm}(150 \mathrm{~K}),{ }^{24}$ and is similar to smaller $\mathrm{CoFe}_{2} \mathrm{O}_{4}$ nanoparticles of $12 \mathrm{~nm}^{25}$ Given the lower Co-ferrite content in CSS and its larger size, it clearly 
shows that exchange coupling contributes to the enhancement of $\mathrm{T}_{\mathrm{B}}$ in CSS.

The FC $M(H)$ curve recorded for CSS at $10 \mathrm{~K}$ after cooling under a field of $7 \mathrm{~T}$ showed a wide-open hysteresis cycle corresponding to $H_{\mathrm{C}}$ of $15000 \mathrm{Oe}$ and a very small shift to negative fields corresponding to an exchange field $\left(H_{\mathrm{E}}\right)$ of 500 Oe. In contrast, a very large shift corresponding to $H_{\mathrm{E}}$ of 5000 Oe was observed for CS which is ascribed to strong exchange bias coupling at the $\mathrm{Fe}_{3-\delta} \mathrm{O}_{4} / \mathrm{CoO}$ interface. ${ }^{5,12}$ Therefore, we expect that the contribution of this phenomenon to $T_{\mathrm{B}}$ enhancement in CSS is negligible. It confirmed that the $\mathrm{CoO}$ shell, which is very thin at the surface of the $\mathrm{Fe}_{3-\delta} \mathrm{O}_{4}$ core, mostly vanished in CSS and became Co-ferrite upon the third decomposition step. The smooth profiles of the $\mathrm{M}(\mathrm{H})$ curves agree with the strong exchange coupling of soft $\mathrm{Fe}_{3-\delta} \mathrm{O}_{4}$ and hard Co-ferrite phases. It results in the nonsaturation of the $M(H)$ curves in contrast to $\mathrm{C}$ which agree with the high magnetic anisotropy of exchange coupled nanoparticles. The magnetization of CSS at $7 \mathrm{~T}(72 \mathrm{emu} / \mathrm{g})$, which is dramatically higher than that of $\mathrm{CS}(41 \mathrm{emu} / \mathrm{g})$, also confirmed the transformation of $\mathrm{CoO}$ in Co-doped ferrite $\left(\mathrm{M}_{\mathrm{S}}\right.$ for $\mathrm{CoFe}_{2} \mathrm{O}_{4}$ nanoparticles is about $80 \mathrm{emu} / \mathrm{g}){ }^{25}$ It is worth noting that such a $M_{\mathrm{S}}$ is even much higher than that of the $\mathrm{Fe}_{3-\delta} \mathrm{O}_{4}$ core $(56 \mathrm{emu} / \mathrm{g}),{ }^{24}$ thus increasing the energy product as required for permanent magnets.

In summary, we have reported on the synthesis of magnetic nanoparticles with an onion-type structure produced by a three-step thermal decomposition process. Besides each decomposition step resulted in the increase of the nanoparticle size, this study shows that the third step accelerated the conversion of the $\mathrm{CoO}$ in Co-ferrite. This is due to two different mechanisms promoted by the high temperature in the reaction medium: (i) the interdiffusion of $\mathrm{Co}$ and $\mathrm{Fe}$ cations at the $\mathrm{Fe}_{3-\delta} \mathrm{O}_{4} / \mathrm{CoO}$ interface promoted by vacancies at the $\mathrm{Fe}_{3-\delta} \mathrm{O}_{4}$ core surface ${ }^{8,17}$ and (ii) the solvation of $\mathrm{CoO}$ in the presence of $\mathrm{Fe}$ monomers (resulting from the third decomposition of $\mathrm{Fe}(\mathrm{Stea})_{2}$ ) which led to Co-ferrite. ${ }^{26}$ According to EDX performed on a large number of CSS nanoparticles, we expect the large amount of $\mathrm{Fe}$ monomers during the third decomposition step in comparison to solvated Co monomers to result in the growth of a second layer of $\mathrm{Fe}_{3-\delta} \mathrm{O}_{4}$ after the formation of the $\mathrm{CoFe}_{2} \mathrm{O}_{4}$ layer.

Therefore, we expect the CSS nanoparticles to consist of two $\mathrm{Fe}_{3-\delta} \mathrm{O}_{4} / \mathrm{Co}$-doped ferrite and $\mathrm{Co}$-doped ferrite $/ \mathrm{Fe}_{3-\delta} \mathrm{O}_{4}$ interfaces which both generate hard-soft exchange coupling. Such a CSS structure resulted in the significant enhancement of $T_{\mathrm{B}}$ and $H_{\mathrm{C}}$ which was not observed in previous works on trimagnetic type nanoparticles. Therefore, room temperature blocked magnetic nanoparticles mostly based on iron oxide with a size not exceeding $16 \mathrm{~nm}$ can be synthesized. Such a strategy opens huge perspectives for the design of rare-earthfree nanoparticles with tunable magnetic properties for a wide range of applications including high density data storage, therapeutics and sensors. Work is in progress to achieve a deeper understanding of the structure of CSS nanoparticles and the structure-property relationship.
Experimental details; TEM-HAADF, STEM-EELS and EELS analysis on CS; STEM and STEM-HAADF on CSS; STEM HAADF and FFT on selected area; details on FC-ZFC measurements; magnetization curve against a magnetic field of C, CS and CSS at 300 and $10 \mathrm{~K}$; table of the magnetic characteristics of $\mathrm{C}, \mathrm{CS}$ and CSS (PDF)

\section{AUTHOR INFORMATION}

\section{Corresponding Author}

*benoit.pichon@ipcms.unistra.fr ORCID ${ }^{\circ}$

Kevin Sartori: 0000-0002-4246-5856

Sylvie Begin-Colin: 0000-0002-2293-2226

Benoit P. Pichon: 0000-0003-3708-6461

\section{Notes}

The authors declare no competing financial interest.

\section{ACKNOWLEDGMENTS}

K.S. was supported by a Ph.D. grant from the French Agence Nationale de la Recherche (ANR) under the reference ANR11-LABX-0058-NIE within the Investissement d'Avenir program ANR-10-IDEX-0002-02 and SOLEIL synchrotron/ Laboratoire Léon Brillouin fellowship. The authors are grateful to SOLEIL synchrotron for providing the access to DEIMOS beamline.

\section{REFERENCES}

(1) López-Ortega, A.; Estrader, M.; Salazar-Alvarez, G.; Roca, A. G.; Nogués, J. Applications of Exchange Coupled Bi-Magnetic Hard/Soft and Soft/Hard Magnetic Core/Shell Nanoparticles. Phys. Rep. 2015, $553,1-32$.

(2) Gutfleisch, O.; Willard, M. A.; Brück, E.; Chen, C. H.; Sankar, S. G.; Liu, J. P. Magnetic Materials and Devices for the 21st Century: Stronger, Lighter, and More Energy Efficient. Adv. Mater. 2011, 23 (7), 821 .

(3) Bedanta, S.; Kleemann, W. Supermagnetism. J. Phys. D: Appl. Phys. 2009, 42 (1), No. 013001.

(4) Nogués, J.; Sort, J.; Langlais, V.; Skumryev, V.; Suriñach, S.; Muñoz, J. S.; Baró, M. D. Exchange Bias in Nanostructures. Phys. Rep. 2005, 422 (3), 65-117.

(5) Liu, X.; Pichon, B. P.; Ulhaq, C.; Lefevre, C.; Greneche, J.-M.; Begin, D.; Begin-Colin, S. Systematic Study of Exchange Coupling in Core-Shell Fe3-DO4@CoO Nanoparticles. Chem. Mater. 2015, 27 (11), 4073.

(6) Song, Q.; Zhang, Z. J. Controlled Synthesis and Magnetic Properties of Bimagnetic Spinel Ferrite $\mathrm{CoFe}_{2} \mathrm{O}_{4}$ and $\mathrm{MnFe}_{2} \mathrm{O}_{4}$ Nanocrystals with Core-Shell Architecture. J. Am. Chem. Soc. 2012, 134 (24), 10182.

(7) Chai, Y.; Feng, F.; Li, Q.; Yu, C.; Feng, X.; Lu, P.; Yu, X.; Ge, M.; Wang, X.; Yao, L. One-Pot Synthesis of High-Quality Bimagnetic Core/Shell Nanocrystals with Diverse Exchange Coupling. J. Am. Chem. Soc. 2019, 141, 3366.

(8) Lopez-Ortega, A.; Estrader, M.; Salazar-Alvarez, G.; Estrade, S.; Golosovsky, I. V.; Dumas, R. K.; Keavney, D. J.; Vasilakaki, M.; Trohidou, K. N.; Sort, J.; Peiro, F.; Surinach, S.; Baro, M. D.; Nogués, J. Strongly Exchange Coupled Inverse Ferrimagnetic Soft/Hard, MnxFe3-XO4/FexMn3-XO4, Core/Shell Heterostructured Nanoparticles. Nanoscale 2012, 4 (16), 5138.

(9) Skoropata, E.; Desautels, R. D.; Chi, C. C.; Ouyang, H.; Freeland, J. W.; van Lierop, J. Magnetism of Iron Oxide Based CoreShell Nanoparticles from Interface Mixing with Enhanced Spin-Orbit Coupling. Phys. Rev. B: Condens. Matter Mater. Phys. 2014, 89 (2), No. 024410.

(10) Tartaj, P.; Morales, M. P.; Gonzalez-Carreño, T.; VeintemillasVerdaguer, S.; Serna, C. J. The Iron Oxides Strike Back: From 
Biomedical Applications to Energy Storage Devices and Photoelectrochemical Water Splitting. Adv. Mater. 2011, 23 (44), 5243.

(11) López-Ortega, A.; Tobia, D.; Winkler, E.; Golosovsky, I. V.; Salazar-Alvarez, G.; Estradé, S.; Estrader, M.; Sort, J.; González, M. A.; Surinach, S.; et al. Size-Dependent Passivation Shell and Magnetic Properties in Antiferromagnetic/Ferrimagnetic Core/Shell MnO Nanoparticles. J. Am. Chem. Soc. 2010, 132 (27), 9398.

(12) Baaziz, W.; Pichon, B. P.; Lefevre, C.; Ulhaq-Bouillet, C.; Greneche, J.-M.; Toumi, M.; Mhiri, T.; Begin-Colin, S. High Exchange Bias in Fe3O4@CoO Core Shell Nanoparticles Synthesized by a One-Pot Seed-Mediated Growth Method. J. Phys. Chem. C 2013, 117 (21), 11436.

(13) Lima, E.; Winkler, E. L.; Tobia, D.; Troiani, H. E.; Zysler, R. D.; Agostinelli, E.; Fiorani, D. Bimagnetic CoO Core/CoFe ${ }_{2} \mathrm{O}_{4}$ Shell Nanoparticles: Synthesis and Magnetic Properties. Chem. Mater. 2012, 24 (3), 512-516.

(14) Lavorato, G. C.; Lima, E.; Troiani, H. E.; Zysler, R. D.; Winkler, E. L. Tuning the Coercivity and Exchange Bias by Controlling the Interface Coupling in Bimagnetic Core/Shell Nanoparticles. Nanoscale 2017, 9 (29), 10240-10247.

(15) De Toro, J. A.; Marques, D. P.; Muñiz, P.; Skumryev, V.; Sort, J.; Givord, D.; Nogués, J. High Temperature Magnetic Stabilization of Cobalt Nanoparticles by an Antiferromagnetic Proximity Effect. Phys. Rev. Lett. 2015, 115 (5), No. 057201.

(16) Daffé, N.; Sikora, M.; Rovezzi, M.; Bouldi, N.; Gavrilov, V.; Neveu, S.; Choueikani, F.; Ohresser, P.; Dupuis, V.; Taverna, D.; Gloter, A.; Arrio, M.-A.; Sainctavit, P.; Juhin, A. Nanoscale Distribution of Magnetic Anisotropies in Bimagnetic Soft CoreHard Shell MnFe2O4@CoFe2O4 Nanoparticles. Adv. Mater. Interfaces 2017, 4 (22), 1700599.

(17) Sartori, K.; Cotin, G.; Ulhaq, C.; Lefevre, C.; Halté, V.; BéginColin, S.; Choueikani, F.; Pichon, B. P. Strong Interfacial Coupling through Exchange Interactions in Soft/Hard Core-Shell Nanoparticles as Function of Cationic Distribution. Nanoscale 2019, DOI: 10.1039/ C9NR02323B.

(18) Salazar-Alvarez, G.; Lidbaum, H.; Lopez-Ortega, A.; Estrader, M.; Leifer, K.; Sort, J.; Surinach, S.; Baro, M. D.; Nogues, J. Two-, Three-, and Four-Component Magnetic Multilayer Onion Nanoparticles Based on Iron Oxides and Manganese Oxides. J. Am. Chem. Soc. 2011, 133 (42), 16738.

(19) Krycka, K. L.; Borchers, J. A.; Laver, M.; Salazar-Alvarez, G.; Lopez-Ortega, A.; Estrader, M.; Surinach, S.; Baro, M. D.; Sort, J.; Nogués, J. Correlating Material-Specific Layers and Magnetic Distributions within Onion-like $\mathrm{Fe} 3 \mathrm{O} 4 / \mathrm{MnO} / \mathrm{g}-\mathrm{Mn} 2 \mathrm{O} 3$ Core/Shell Nanoparticles. J. Appl. Phys. 2013, 113 (17), 17B531.

(20) Gavrilov-Isaac, V.; Neveu, S.; Dupuis, V.; Taverna, D.; Gloter, A.; Cabuil, V. Synthesis of Trimagnetic Multishell MnFe2O4@ CoFe2O4@NiFe2O4 Nanoparticles. Small 2015, 11 (22), 26142618.

(21) Ohresser, P.; Otero, E.; Choueikani, F.; Chen, K.; Stanescu, S.; Deschamps, F.; Moreno, T.; Polack, F.; Lagarde, B.; Daguerre, J.-P.; Marteau, F.; Scheurer, F.; Joly, L.; Kappler, J.-P.; Muller, B.; Bunau, O.; Sainctavit, P. DEIMOS: A Beamline Dedicated to Dichroism Measurements in the 350-2500 EV Energy Range. Rev. Sci. Instrum. 2014, 85 (1), No. 013106.

(22) Daffé, N.; Choueikani, F.; Neveu, S.; Arrio, M.-A.; Juhin, A.; Ohresser, P.; Dupuis, V.; Sainctavit, P. Magnetic Anisotropies and Cationic Distribution in $\mathrm{CoFe} 2 \mathrm{O} 4$ Nanoparticles Prepared by CoPrecipitation Route: Influence of Particle Size and Stoichiometry. J. Magn. Magn. Mater. 2018, 460, 243-252.

(23) Bruvera, I. J.; Mendoza Zélis, P.; Pilar Calatayud, M.; Goya, G. F.; Sánchez, F. H. Determination of the Blocking Temperature of Magnetic Nanoparticles: The Good, the Bad, and the Ugly. J. Appl. Phys. 2015, 118 (18), 184304.

(24) Baaziz, W.; Pichon, B. P.; Fleutot, S.; Liu, Y.; Lefevre, C.; Greneche, J.-M.; Toumi, M.; Mhiri, T.; Begin-Colin, S. Magnetic Iron Oxide Nanoparticles: Reproducible Tuning of the Size and Nanosized-Dependent Composition, Defects, and Spin Canting. J. Phys. Chem. C 2014, 118 (7), 3795.
(25) Song, Q.; Zhang, Z. J. Shape Control and Associated Magnetic Properties of Spinel Cobalt Ferrite Nanocrystals. J. Am. Chem. Soc. 2004, 126 (19), 6164-6168.

(26) Sytnyk, M.; Kirchschlager, R.; Bodnarchuk, M. I.; Primetzhofer, D.; Kriegner, D.; Enser, H.; Stangl, J.; Bauer, P.; Voith, M.; Hassel, A. W.; et al. Tuning the Magnetic Properties of Metal Oxide Nanocrystal Heterostructures by Cation Exchange. Nano Lett. 2013, 13 (2), 586593. 